\title{
Fixed Point Theorems for Generalized Mizoguchi-Takahashi Graphic Contractions
}

\author{
Nawab Hussain, ${ }^{1}$ Jamshaid Ahmad, ${ }^{2}$ and Marwan Amin Kutbi ${ }^{1}$ \\ ${ }^{1}$ Department of Mathematics, King Abdulaziz University, P.O. Box 80203, Jeddah 21589, Saudi Arabia \\ ${ }^{2}$ Department of Mathematics, University of Sargodha (Subcampus Bhakkar), Bhakkar, Pakistan
}

Correspondence should be addressed to Jamshaid Ahmad; jamshaid_jasim@yahoo.com

Received 9 April 2016; Revised 27 June 2016; Accepted 28 June 2016

Academic Editor: Adrian Petrusel

Copyright (C) 2016 Nawab Hussain et al. This is an open access article distributed under the Creative Commons Attribution License, which permits unrestricted use, distribution, and reproduction in any medium, provided the original work is properly cited.

\begin{abstract}
Remarkable feature of contractions is associated with the concept Mizoguchi-Takahashi function. For the purpose of extension and modification of classical ideas related with Mizoguchi-Takahashi contraction, we define generalized Mizoguchi-Takahashi Gcontractions and establish some generalized fixed point theorems regarding these contractions in this paper. Some applications to the construction of a fixed point of multivalued mappings in $\varepsilon$-chainable metric space are also discussed.
\end{abstract}

\section{Introduction}

In 1922, Banach [1] presented a revolutionary contraction principle (namely, Banach contraction principle) in which Picard iteration process was used for the evaluation of a fixed point. This principle guarantees the existence and uniqueness of fixed points of certain self-mappings on metric spaces and provides a constructive method to find those fixed points. The Banach contraction principle was also used to establish the existence of a unique solution for a nonlinear integral equation [2]. For instance, it has been used to show the existence of solutions of nonlinear Volterra integral equations and nonlinear integrodifferential equations in Banach spaces and to show the convergence of algorithms in computational mathematics. Because of its importance and usefulness for mathematical theory, it has become a very popular tool in solving existence problems in many directions. Several authors have obtained various extensions and generalizations of Banach's theorem by defining a variety of contractive type conditions for self- and non-self-mappings on metric spaces.

Following the Banach contraction principle, Nadler [3] introduced the concept of multivalued contractions using the Hausdorff metric and established that a multivalued contraction possesses a fixed point in a complete metric space (see [4-14]). Subsequently, in 1969, Mizoguchi and Takahashi
[15] proved the following famous result as a generalization of Nadler's fixed point theorem [3].

Theorem 1 (see [15]). Let $(X, d)$ be a complete metric space and let $S: X \rightarrow C B(X)$ be a multivalued mapping. Assume that

$$
H(S(x), S(y)) \leq \varphi(d(x, y)) d(x, y)
$$

for all $x, y \in X$, where $\varphi:[0, \infty) \rightarrow[0,1)$ is such that

$$
\lim _{v \rightarrow u^{+}} \sup \varphi(v)<1
$$

for all $u \in[0, \infty)$. Then, $S$ has a fixed point.

We denote by $\Omega$ the set of all functions $\varphi:[0, \infty) \rightarrow[0,1)$ satisfying inequalities (1) and (2).

Recently, Javahernia et al. [16] generalized the abovementioned function by introducing the notion of generalized Mizoguchi-Takahashi function in such a way.

Definition 2 (see [16]). A function $\beta: \mathbb{R} \times \mathbb{R} \rightarrow \mathbb{R}$ is called a generalized Mizoguchi-Takahashi function (shortly, generalized MT-function) if the following conditions hold:

$$
\left(a_{1}\right) 0<\beta(u, v)<1 \text { for all } u, v>0 \text {; }
$$


$\left(a_{2}\right)$ for any bounded sequence $\left\{u_{n}\right\} \subset(0,+\infty)$ and any nonincreasing sequence $\left\{v_{n}\right\} \subset(0,+\infty)$, one has

$$
\lim _{n \rightarrow \infty} \sup \beta\left(u_{n}, v_{n}\right)<1 \text {. }
$$

Consistent with Javahernia et al. [16], we denote by $\Lambda$ the set of all functions $\beta: \mathbb{R} \times \mathbb{R} \rightarrow \mathbb{R}$ satisfying conditions $\left(a_{1}\right)$ $\left(a_{2}\right)$.

On the other hand, Jachymski [17] proved some fixed point results in metric spaces endowed with a graph and generalized simultaneously Banach's contraction principle from metric and partially ordered metric spaces in 2008. Consistent with Jachymski, let $(X, d)$ be a metric space and let $\Delta$ denote the diagonal of the Cartesian product $X \times$ $X$. Consider a directed graph $G$ such that the set $V(G)$ of its vertices coincides with $X$ and the set $E(G)$ of its edges contains all loops; that is, $E(G) \supseteq \Delta$. We assume $G$ has no parallel edges and so we can identify $G$ with the pair $(V(G), E(G))$. Moreover, we may treat $G$ as a weighted graph (see [17]) by assigning to each edge the distance between its vertices. If $x$ and $y$ are vertices in a graph $G$, then a path in $G$ from $x$ to $y$ of length $N(N \in \mathbb{N})$ is a sequence $\left\{x_{i}\right\}_{i=0}^{N}$ of $N+1$ vertices such that $x_{0}=x, x_{N}=y$, and $\left(x_{n-1}, x_{n}\right) \in E(G)$ for each $i=1, \ldots, N$. A graph $G$ is connected if there is a path between any two vertices. $G$ is weakly connected if $\widetilde{G}$ is connected.

In 2010, Beg et al. [18] obtained sufficient conditions for the existence of a fixed point of multivalued mapping in the complete metric space endowed with a graph. For more details in this direction, we refer the reader to [19-24].

Recently, Sultana and Vetrivel [25] introduced the notion of Mizoguchi-Takahashi G-contraction in this way.

Definition 3 (see [25]). Let $(X, d)$ be metric space endowed with a graph and let $S: X \rightarrow C B(X)$ be a multivalued mapping. Then, $S$ is called a Mizoguchi-Takahashi $G$-contraction if

(1) for all $x, y \in X$, with $x \neq y$ and $(x, y) \in E(G)$,

$$
H(S(x), S(y)) \leq \varphi(d(x, y)) d(x, y),
$$

where $\varphi \in \Omega$;

(2) $u \in S(x)$ and $v \in S(y)$ are such that $d(u, v) \leq d(x, y)$; then, $(u, v) \in E(G)$.

They established the following fixed point theorem as main result regarding Mizoguchi-Takahashi G-contraction.

Theorem 4 (see [25]). Let $(X, d)$ be a complete metric space endowed with a graph and $S: X \rightarrow C B(X)$ a MizoguchiTakahashi G-contraction. Assume that there exist $N \in \mathbb{N}$ and $x_{0} \in X$ such that

(1) $\left[x_{0}\right]_{G}^{N} \cap S\left(x_{0}\right) \neq 0$;

(2) for any sequence $\left\{x_{n}\right\}_{n \in \mathbb{N}} \in X$, if $x_{n} \rightarrow x$ and $x_{n} \in$ $\left[x_{n-1}\right]_{G}^{N} \cap S\left(x_{n-1}\right)$ for all $n \in \mathbb{N}$, then, there is a subsequence $\left\{x_{n_{m}}\right\}_{m \in \mathbb{N}} \in X$ such that $\left(x_{n_{m}}, x\right) \in E(G)$ for each $m \in \mathbb{N}$.
Then, $S$ has a fixed point and the sequence $\left\{x_{n}\right\}_{n \in \mathbb{N}} \in X$ converges to the fixed point of $S$.

The purpose of this paper is to define generalized Mizoguchi-Takahashi G-contractions and prove some generalized fixed point theorems for these contractions.

The following lemma of Sultana and Vetrivel [25] for single-valued mappings is crucial for some of our proofs.

Lemma 5. Let $S: X \rightarrow X$ be a single-valued mapping satisfying

$$
d(S(x), S(y)) \leq \varphi(d(x, y)) d(x, y)
$$

for all $(x, y) \in E(G)$ with $x \neq y$. Let $p, q \in X$ be two points such that there is a path $\left(x_{i}\right)_{i=0}^{N}$ from $p$ to $q$. Then, there exist $\lambda \in[0,1)$ and $n_{0} \in \mathbb{N}$ such that

$$
d\left(S^{n}(p), S^{n}(q)\right) \leq C \lambda^{n}
$$

for all $n \geq n_{0}$, where $C \geq 0$.

\section{Main Results}

We start this section with the definition of a generalized Mizoguchi-Takahashi G-contraction.

Definition 6. Let $(X, d)$ be metric space endowed with a graph and $S: X \rightarrow C B(X)$. Then, $S$ is said to be generalized Mizoguchi-Takahashi $G$-contraction if

(1) for all $x, y \in X$, with $x \neq y$ and $(x, y) \in E(G)$,

$$
\begin{aligned}
& H(S(x), S(y)) \\
& \quad \leq \beta(H(S(x), S(y)), d(x, y)) d(x, y),
\end{aligned}
$$

where $\beta \in \Lambda$;

(2) $u \in S(x)$ and $v \in S(y)$ are such that $d(u, v) \leq d(x, y)$; then, $(u, v) \in E(G)$.

The following remark illustrates our main definition.

Remark 7. Taking $\beta(u, v)=\varphi(v)$ in Definition 6, we get Definition 3 which is the main definition of [25].

Now, we state our main result of this section.

Theorem 8. Let $(X, d)$ be a complete metric space endowed with a graph and $S: X \rightarrow C B(X)$ a generalized MizoguchiTakahashi G-contraction. Assume that there exist $N \in \mathbb{N}$ and $x_{0} \in X$ such that

(1) $\left[x_{0}\right]_{G}^{N} \cap S\left(x_{0}\right) \neq 0$;

(2) for any sequence $\left\{x_{n}\right\}_{n \in \mathbb{N}} \in X$, if $x_{n} \rightarrow x$ and $x_{n} \in\left[x_{n-1}\right]_{G}^{N} \cap S\left(x_{n-1}\right)$ for all $n \in \mathbb{N}$, then there is a subsequence $\left\{x_{n_{m}}\right\}_{m \in \mathbb{N}} \in X$ such that $\left(x_{n_{m}}, x\right) \in E(G)$ for each $m \in \mathbb{N}$.

Then, $S$ has a fixed point and the sequence $\left\{x_{n}\right\}_{n \in \mathbb{N}} \in X$ converges to a fixed point of S. 
Proof. Let $x_{1} \in\left[x_{0}\right]_{G}^{N} \cap S\left(x_{0}\right)$. Then, there is a path $\left(y^{j}\right)_{j=0}^{N}$ in $G$ from $x_{0}$ to $x_{1}$; that is, $y^{0}=x_{0}, y^{N}=x_{1}$, and $\left(y^{j-1}, y^{j}\right) \in E(G)$ for each $j=1,2, \ldots, N$. Select a positive integer $m_{1}^{1}$ such that

$$
\begin{aligned}
& \beta^{m_{1}^{1}}\left(H\left(S\left(y^{0}\right), S\left(y^{1}\right)\right), d\left(y^{0}, y^{1}\right)\right) \\
& \quad+\beta\left(H\left(S\left(y^{0}\right), S\left(y^{1}\right)\right), d\left(y^{0}, y^{1}\right)\right) d\left(y^{0}, y^{1}\right) \\
& \quad<d\left(y^{0}, y^{1}\right) .
\end{aligned}
$$

Since $\left(y^{0}, y^{1}\right) \in E(G)$, it follows from (7) that

$$
\begin{aligned}
& H\left(S\left(y^{0}\right), S\left(y^{1}\right)\right) \\
& \quad \leq \beta\left(H\left(S\left(y^{0}\right), S\left(y^{1}\right)\right), d\left(y^{0}, y^{1}\right)\right) d\left(y^{0}, y^{1}\right)
\end{aligned}
$$

and, also, since $x_{1} \in S\left(x_{0}=y^{0}\right)$, by the definition of Hausdorff metric, there exists $y_{1}^{1} \in S\left(y^{1}\right)$ such that

$$
\begin{aligned}
d\left(x_{1}, y_{1}^{1}\right) \leq & H\left(S\left(y^{0}\right), S\left(y^{1}\right)\right) \\
& +\beta^{m_{1}^{1}}\left(H\left(S\left(y^{0}\right), S\left(y^{1}\right)\right), d\left(y^{0}, y^{1}\right)\right) .
\end{aligned}
$$

From (9), we have

$$
\begin{aligned}
d\left(x_{1}, y_{1}^{1}\right) & \\
\leq & \beta\left(H\left(S\left(y^{0}\right), S\left(y^{1}\right)\right), d\left(y^{0}, y^{1}\right)\right) d\left(y^{0}, y^{1}\right) \\
& +\beta^{m_{1}^{1}}\left(H\left(S\left(y^{0}\right), S\left(y^{1}\right)\right), d\left(y^{0}, y^{1}\right)\right) .
\end{aligned}
$$

It follows from (8) and (11) that $d\left(x_{1}, y_{1}^{1}\right)<d\left(y^{0}, y^{1}\right)$. Thus, $\left(x_{1}, y_{1}^{1}\right) \in E(G)$. Select a positive integer $m_{1}^{2}$ such that

$$
\begin{aligned}
\beta^{m_{1}^{2}} & \left(H\left(S\left(y^{1}\right), S\left(y^{2}\right)\right), d\left(y^{1}, y^{2}\right)\right) \\
& +\beta\left(H\left(S\left(y^{1}\right), S\left(y^{2}\right)\right), d\left(y^{1}, y^{2}\right)\right) d\left(y^{1}, y^{2}\right) \\
< & d\left(y^{1}, y^{2}\right) .
\end{aligned}
$$

Since $\left(x_{1}, y_{1}^{1}\right) \in E(G)$, it follows from (7) that

$$
\begin{aligned}
& H\left(S\left(y^{1}\right), S\left(y^{2}\right)\right) \\
& \quad \leq \beta\left(H\left(S\left(y^{1}\right), S\left(y^{2}\right)\right), d\left(y^{1}, y^{2}\right)\right) d\left(y^{1}, y^{2}\right) .
\end{aligned}
$$

Since $y_{1}^{1} \in S\left(y^{1}\right)$, by the definition of Hausdorff metric, there exists $y_{1}^{2} \in S\left(y^{2}\right)$ such that

$$
\begin{aligned}
d\left(y_{1}^{1}, y_{1}^{2}\right) \leq & H\left(S\left(y^{1}\right), S\left(y^{2}\right)\right) \\
& +\beta^{m_{1}^{2}}\left(H\left(S\left(y^{1}\right), S\left(y^{2}\right)\right), d\left(y^{1}, y^{2}\right)\right) .
\end{aligned}
$$

From (13), we have

$$
\begin{aligned}
& d\left(y_{1}^{1}, y_{1}^{2}\right) \\
& \leq \beta\left(H\left(S\left(y^{1}\right), S\left(y^{2}\right)\right), d\left(y^{1}, y^{2}\right)\right) d\left(y^{1}, y^{2}\right) \\
& \quad+\beta^{m_{1}^{2}}\left(H\left(S\left(y^{1}\right), S\left(y^{2}\right)\right), d\left(y^{1}, y^{2}\right)\right) .
\end{aligned}
$$

It follows from (12) and (15) that $d\left(y_{1}^{1}, y_{1}^{2}\right)<d\left(y^{1}, y^{2}\right)$. Thus, $\left(y_{1}^{1}, y_{1}^{2}\right) \in E(G)$. Continuing the abovementioned procedure, we have

$$
\begin{aligned}
y_{1}^{j-1} & \in S\left(y^{j-1}\right), \\
\left(y_{1}^{j-2}, y_{1}^{j-1}\right) & \in E(G)
\end{aligned}
$$

and, for a chosen positive integer $m_{1}^{j}$ for each $j=3,4, \ldots, N$,

$$
\begin{aligned}
\beta & \left.H\left(S\left(y^{j-1}\right), S\left(y^{j}\right)\right), d\left(y^{j-1}, y^{j}\right)\right) d\left(y^{j-1}, y^{j}\right) \\
& +\beta^{m_{1}^{j}}\left(H\left(S\left(y^{j-1}\right), S\left(y^{j}\right)\right), d\left(y^{j-1}, y^{j}\right)\right) \\
< & d\left(y^{j-1}, y^{j}\right) .
\end{aligned}
$$

Since $\left(y_{1}^{j-2}, y_{1}^{j-1}\right) \in E(G)$, it follows from (7) that

$$
\begin{aligned}
& H\left(S\left(y^{j-1}\right), S\left(y^{j}\right)\right) \leq \beta\left(H\left(S\left(y^{j-1}\right), S\left(y^{j}\right)\right),\right. \\
& \left.\quad d\left(y^{j-1}, y^{j}\right)\right) d\left(y^{j-1}, y^{j}\right) .
\end{aligned}
$$

Since $y_{1}^{j-1} \in S\left(y^{j-1}\right)$, by the definition of Hausdorff metric, there exists $y_{1}^{j} \in S\left(y^{j}\right)$ such that

$$
\begin{aligned}
& d\left(y_{1}^{j-1}, y_{1}^{j}\right) \\
& \leq H\left(S\left(y^{j-1}\right), S\left(y^{j}\right)\right) \\
&+\beta^{m_{1}^{j}}\left(H\left(S\left(y^{j-1}\right), S\left(y^{j}\right)\right), d\left(y^{j-1}, y^{j}\right)\right) \\
& \leq \beta\left(H\left(S\left(y^{j-1}\right), S\left(y^{j}\right)\right), d\left(y^{j-1}, y^{j}\right)\right) d\left(y^{j-1}, y^{j}\right) \\
&+\beta^{m_{1}^{j}}\left(H\left(S\left(y^{j-1}\right), S\left(y^{j}\right)\right), d\left(y^{j-1}, y^{j}\right)\right) \\
&< d\left(y^{j-1}, y^{j}\right) ;
\end{aligned}
$$

that is, $\left(y_{1}^{j-1}, y_{1}^{j}\right) \in E(G)$ for each $j=3,4, \ldots, N$. Set $x_{2}=$ $y_{1}^{N} \in S\left(y^{N}=x_{1}\right)$. Then, there is a path $\left(y_{1}^{j}\right)_{j=0}^{N}$ in $G$ from $x_{1}$ to $x_{2}$; that is, $y_{1}^{0}=x_{1}, y_{1}^{N}=x_{2}$, and $\left(y_{1}^{j-1}, y_{1}^{j}\right) \in E(G)$ for each $j=1,2, \ldots, N$. Hence, $x_{2} \in\left[x_{1}\right]_{G}^{N} \cap S\left(x_{1}\right)$. Select a positive integer $m_{2}^{1}>m_{1}^{1}$ such that

$$
\begin{aligned}
\beta^{m_{2}^{1}} & \left(H\left(S\left(y_{1}^{0}\right), S\left(y_{1}^{1}\right)\right), d\left(y_{1}^{0}, y_{1}^{1}\right)\right) \\
& +\beta\left(H\left(S\left(y_{1}^{0}\right), S\left(y_{1}^{1}\right)\right), d\left(y_{1}^{0}, y_{1}^{1}\right)\right) d\left(y_{1}^{0}, y_{1}^{1}\right) \\
< & d\left(y_{1}^{0}, y_{1}^{1}\right) .
\end{aligned}
$$

Since $\left(y_{1}^{0}, y_{1}^{1}\right) \in E(G)$, it follows from (7) that

$$
\begin{aligned}
& H\left(S\left(y_{1}^{0}\right), S\left(y_{1}^{1}\right)\right) \\
& \quad \leq \beta\left(H\left(S\left(y_{1}^{0}\right), S\left(y_{1}^{1}\right)\right), d\left(y_{1}^{0}, y_{1}^{1}\right)\right) d\left(y_{1}^{0}, y_{1}^{1}\right)
\end{aligned}
$$


and, also, $x_{2} \in S\left(x_{1}=y_{1}^{0}\right)$, which gives, by the definition of Hausdorff metric, the notion that there exists $y_{2}^{1} \in S\left(y_{1}^{1}\right)$ such that

$$
\begin{aligned}
& d\left(x_{2}, y_{2}^{1}\right) \\
& \leq H\left(S\left(y_{1}^{0}\right), S\left(y_{1}^{1}\right)\right) \\
&+\beta^{m_{2}^{1}}\left(H\left(S\left(y_{1}^{0}\right), S\left(y_{1}^{1}\right)\right), d\left(y_{1}^{0}, y_{1}^{1}\right)\right) \\
& \leq \beta\left(H\left(S\left(y_{1}^{0}\right), S\left(y_{1}^{1}\right)\right), d\left(y_{1}^{0}, y_{1}^{1}\right)\right) d\left(y_{1}^{0}, y_{1}^{1}\right) \\
&+\beta^{m_{2}^{1}}\left(H\left(S\left(y_{1}^{0}\right), S\left(y_{1}^{1}\right)\right), d\left(y_{1}^{0}, y_{1}^{1}\right)\right) .
\end{aligned}
$$

It follows from (20) and (22) that $d\left(x_{2}, y_{2}^{1}\right)<d\left(y_{1}^{0}, y_{1}^{1}\right)$ and so $\left(x_{2}, y_{2}^{1}\right) \in E(G)$. Select a positive integer $m_{2}^{2}>m_{1}^{2}$ such that

$$
\begin{aligned}
\beta^{m_{2}^{2}} & \left(H\left(S\left(y_{1}^{1}\right), S\left(y_{1}^{2}\right)\right), d\left(y_{1}^{1}, y_{1}^{2}\right)\right) \\
& +\beta\left(H\left(S\left(y_{1}^{1}\right), S\left(y_{1}^{2}\right)\right), d\left(y_{1}^{1}, y_{1}^{2}\right)\right) d\left(y_{1}^{1}, y_{1}^{2}\right) \\
< & d\left(y_{1}^{1}, y_{1}^{2}\right) .
\end{aligned}
$$

Since $\left(x_{2}, y_{2}^{1}\right) \in E(G)$ and $y_{2}^{1} \in S\left(y_{1}^{1}\right)$, it follows from (7) that

$$
\begin{aligned}
& H\left(S\left(y_{1}^{1}\right), S\left(y_{1}^{2}\right)\right) \\
& \quad \leq \beta\left(H\left(S\left(y_{1}^{1}\right), S\left(y_{1}^{2}\right)\right), d\left(y_{1}^{1}, y_{1}^{2}\right)\right) d\left(y_{1}^{1}, y_{1}^{2}\right) .
\end{aligned}
$$

Since $y_{2}^{1} \in S\left(y_{1}^{1}\right)$, by the definition of Hausdorff metric, there exists $y_{2}^{2} \in S\left(y_{1}^{2}\right)$ such that

$$
\begin{aligned}
& d\left(y_{2}^{1}, y_{2}^{2}\right) \\
& \leq H\left(S\left(y_{1}^{1}\right), S\left(y_{1}^{2}\right)\right) \\
&+\beta^{m_{2}^{2}}\left(H\left(S\left(y_{1}^{1}\right), S\left(y_{1}^{2}\right)\right), d\left(y_{1}^{1}, y_{1}^{2}\right)\right) \\
& \leq \beta\left(H\left(S\left(y_{1}^{1}\right), S\left(y_{1}^{2}\right)\right), d\left(y_{1}^{1}, y_{1}^{2}\right)\right) d\left(y_{1}^{1}, y_{1}^{2}\right) \\
&+\beta^{m_{2}^{2}}\left(H\left(S\left(y_{1}^{1}\right), S\left(y_{1}^{2}\right)\right), d\left(y_{1}^{1}, y_{1}^{2}\right)\right) .
\end{aligned}
$$

It follows from (23) and (25) that $d\left(y_{2}^{1}, y_{2}^{2}\right)<d\left(y_{1}^{1}, y_{1}^{2}\right)$ and so $\left(y_{2}^{1}, y_{2}^{2}\right) \in E(G)$. Continuing the abovementioned procedure, we have

$$
y_{2}^{j-1} \in S\left(y_{1}^{j-1}\right),\left(y_{2}^{j-2}, y_{2}^{j-1}\right) \in E(G)
$$

and, for a chosen positive integer $m_{2}^{j}>m_{1}^{j}$ for each $j=$ $3,4, \ldots, N$,

$$
\begin{aligned}
\beta & \left.H\left(S\left(y_{1}^{j-1}\right), S\left(y_{1}^{j}\right)\right), d\left(y_{1}^{j-1}, y_{1}^{j}\right)\right) d\left(y_{1}^{j-1}, y_{1}^{j}\right) \\
& +\beta^{m_{1}^{j}}\left(H\left(S\left(y_{1}^{j-1}\right), S\left(y_{1}^{j}\right)\right), d\left(y_{1}^{j-1}, y_{1}^{j}\right)\right) \\
< & d\left(y_{1}^{j-1}, y_{1}^{j}\right) .
\end{aligned}
$$

As $\left(y_{2}^{j-2}, y_{2}^{j-1}\right) \in E(G)$, from (7), we have

$$
\begin{aligned}
& H\left(S\left(y_{1}^{j-1}\right), S\left(y_{1}^{j}\right)\right) \leq \beta\left(H\left(S\left(y_{1}^{j-1}\right), S\left(y_{1}^{j}\right)\right),\right. \\
& \left.\quad d\left(y_{1}^{j-1}, y_{1}^{j}\right)\right) d\left(y_{1}^{j-1}, y_{1}^{j}\right) .
\end{aligned}
$$

Since $y_{2}^{j-1} \in S\left(y_{1}^{j-1}\right)$, by the definition of Hausdorff metric, there exists $y_{2}^{j} \in S\left(y_{1}^{j}\right)$ such that

$$
\begin{aligned}
d & \left(y_{2}^{j-1}, y_{2}^{j}\right) \\
\leq & H\left(S\left(y_{1}^{j-1}\right), S\left(y_{1}^{j}\right)\right) \\
& +\beta^{m_{1}^{j}}\left(H\left(S\left(y_{1}^{j-1}\right), S\left(y_{1}^{j}\right)\right), d\left(y_{1}^{j-1}, y_{1}^{j}\right)\right) \\
\leq & \beta\left(H\left(S\left(y_{1}^{j-1}\right), S\left(y_{1}^{j}\right)\right), d\left(y_{1}^{j-1}, y_{1}^{j}\right)\right) d\left(y_{1}^{j-1}, y_{1}^{j}\right) \\
& +\beta^{m_{1}^{j}}\left(H\left(S\left(y_{1}^{j-1}\right), S\left(y_{1}^{j}\right)\right), d\left(y_{1}^{j-1}, y_{1}^{j}\right)\right) \\
< & d\left(y_{1}^{j-1}, y_{1}^{j}\right) .
\end{aligned}
$$

Hence, $\left(y_{2}^{j-1}, y_{2}^{j}\right) \in E(G)$ for each $j=3,4, \ldots, N$. Set $x_{3}=$ $y_{2}^{N} \in S\left(y_{1}^{N}=x_{2}\right)$. Then, there is a path $\left(y_{2}^{j}\right)_{j=0}^{N}$ in $G$ from $x_{2}$ to $x_{3}$; that is, $y_{2}^{0}=x_{2}, y_{2}^{N}=x_{3}$, and $\left(y_{2}^{j-1}, y_{2}^{j}\right) \in E(G)$ for each $j=1,2, \ldots, N$. Hence, $x_{3} \in\left[x_{2}\right]_{G}^{N} \cap S\left(x_{2}\right)$. Continuing in this way for each $n \in \mathbb{N}$, we construct $x_{n+1} \in\left[x_{n}\right]_{G}^{N} \cap S\left(x_{n}\right)$ by generating a path $\left(y_{n}^{j}\right)_{j=0}^{N}$ in $G$ from $x_{n}$ to $x_{n+1}$; that is, $y_{n}^{0}=$ $x_{n}, y_{n}^{N}=x_{n+1}$, and $y_{n}^{j} \in S\left(y_{n-1}^{j}\right)$ for each $j=1,2, \ldots, N$, and, for a chosen positive integer $m_{n}^{j}$ with $m_{n}^{j}>m_{n-1}^{j}$ for $1 \leq$ $j \leq N$, we have

$$
\begin{aligned}
& \beta\left(H\left(S\left(y_{n-1}^{j-1}\right), S\left(y_{n-1}^{j}\right)\right),\right. \\
& \left.\quad d\left(y_{n-1}^{j-1}, y_{n-1}^{j}\right)\right) d\left(y_{n-1}^{j-1}, y_{n-1}^{j}\right) \\
& \quad+\beta^{m_{n}^{j}}\left(H\left(S\left(y_{n-1}^{j-1}\right), S\left(y_{n-1}^{j}\right)\right), d\left(y_{n-1}^{j-1}, y_{n-1}^{j}\right)\right) \\
& \quad<d\left(y_{n-1}^{j-1}, y_{n-1}^{j}\right) .
\end{aligned}
$$

Since $\left(y_{n}^{j-2}, y_{n}^{j-1}\right) \in E(G)$ and $y_{n}^{j-1} \in S\left(y_{n-1}^{j-1}\right)$, it follows from (7) that

$$
\begin{aligned}
& H\left(S\left(y_{n-1}^{j-1}\right), S\left(y_{n-1}^{j}\right)\right) \leq \beta\left(H\left(S\left(y_{n-1}^{j-1}\right), S\left(y_{n-1}^{j}\right)\right),\right. \\
& \left.\quad d\left(y_{n-1}^{j-1}, y_{n-1}^{j}\right)\right) d\left(y_{n-1}^{j-1}, y_{n-1}^{j}\right) .
\end{aligned}
$$


Since $y_{n}^{j-1} \in S\left(y_{n}^{j-1}\right)$, by the definition of Hausdorff metric, there exists $y_{n}^{j} \in S\left(y_{n-1}^{j}\right)$ such that

$$
\begin{aligned}
& d\left(y_{n}^{j-1}, y_{n}^{j}\right) \leq H\left(S\left(y_{n-1}^{j-1}\right), S\left(y_{n-1}^{j}\right)\right) \\
& \quad+\beta^{m_{n}^{j}}\left(H\left(S\left(y_{n-1}^{j-1}\right), S\left(y_{n-1}^{j}\right)\right), d\left(y_{n-1}^{j-1}, y_{n-1}^{j}\right)\right) \\
& \quad \leq \beta\left(H\left(S\left(y_{n-1}^{j-1}\right), S\left(y_{n-1}^{j}\right)\right),\right. \\
& \left.\quad d\left(y_{n-1}^{j-1}, y_{n-1}^{j}\right)\right) d\left(y_{n-1}^{j-1}, y_{n-1}^{j}\right) \\
& \quad+\beta^{m_{n}^{j}}\left(H\left(S\left(y_{n-1}^{j-1}\right), S\left(y_{n-1}^{j}\right)\right), d\left(y_{n-1}^{j-1}, y_{n-1}^{j}\right)\right) \\
& \quad<d\left(y_{n-1}^{j-1}, y_{n-1}^{j}\right) .
\end{aligned}
$$

Hence, for $1 \leq j \leq N$, we have $\left(y_{n}^{j-1}, y_{n}^{j}\right) \in E(G)$. For $1 \leq j \leq$ $N$, we denote $d_{0}^{j}=d\left(y^{j-1}, y^{j}\right)$ and $d_{n}^{j}=d\left(y_{n}^{j-1}, y_{n}^{j}\right)$. From the abovementioned inequality, we have the notion that $\left\{d_{n}^{j}\right\}_{n \in \mathbb{N}}$ is a monotone nonincreasing sequence of nonnegative real numbers for each $j \geq 1$. Let $d_{n}^{j} \rightarrow r^{j} \geq 0$. By $\left(a_{1}\right)$ and inequality (31), it follows that $\left\{H\left(S\left(y_{n-1}^{j-1}\right), S\left(y_{n-1}^{j}\right)\right)\right\}$ is a bounded sequence. By $\left(a_{2}\right)$, we have

$$
\lim _{n \rightarrow \infty} \sup \beta\left(H\left(S\left(y_{n-1}^{j-1}\right), S\left(y_{n-1}^{j}\right)\right), d\left(y_{n}^{j-1}, y_{n}^{j}\right)\right)
$$

$$
<1 \text {. }
$$

Let $\pi_{n}^{j}=H\left(S\left(y_{n-1}^{j-1}\right), S\left(y_{n-1}^{j}\right)\right)$ for each $1 \leq j \leq N$. Then, there exist positive integers $n_{0}^{j}$ and real numbers $\gamma^{j} \in[0,1)$ such that $\beta\left(\pi_{n}^{j}, d_{n}^{j}\right)<\gamma^{j}$ for each $n \geq n_{0}^{j}$, where

$$
\lim _{n \rightarrow \infty} \sup \beta\left(\pi_{n}^{j}, d_{n}^{j}\right)<\gamma^{j}<1
$$

Hence, for each $1 \leq j \leq N$, we have

$$
\beta\left(\pi_{n}^{j}, d_{n}^{j}\right)<\gamma
$$

for all $n \geq n_{0}$, where $\gamma=\max _{1 \leq j \leq N} \gamma^{j}$ and $n_{0}=\max _{1 \leq j \leq N} n_{0}^{j}$. For $1 \leq j \leq N$ and $n \geq n_{0}+1$, we have

$$
\begin{aligned}
d_{n}^{j} & \leq \beta\left(\pi_{n-1}^{j}, d_{n-1}^{j}\right) d_{n}^{j}+\beta^{m_{n}^{j}}\left(\pi_{n-1}^{j}, d_{n-1}^{j}\right) \leq \cdots \\
& \leq \prod_{s=0}^{n-1} \beta\left(\pi_{s}^{j}, d_{s}^{j}\right) d_{0}^{j}+\sum_{k=1}^{n-1} \prod_{s=k+1}^{n} \beta\left(\pi_{s-1}^{j}, d_{s-1}^{j}\right) \\
& \cdot \beta^{m_{k}^{j}}\left(\pi_{k-1}^{j}, d_{k-1}^{j}\right)+\beta^{m_{n}^{j}}\left(\pi_{n-1}^{j}, d_{n-1}^{j}\right) \\
& \leq \gamma^{n-n_{0}} \prod_{s=0}^{n_{0}} \beta\left(\pi_{s}^{j}, d_{s}^{j}\right) d_{0}^{j} \\
& +\sum_{k=1}^{n-1} \prod_{s=\max \left\{n_{0}+1, k+1\right\}}^{n} \beta\left(\pi_{s-1}^{j}, d_{s-1}^{j}\right) \beta^{m_{k}^{j}}\left(\pi_{k-1}^{j}, d_{k-1}^{j}\right) \\
& +\gamma^{n} .
\end{aligned}
$$

Let us denote the second term of the last inequality by $B$ to get

$$
\begin{aligned}
B= & \sum_{k=1}^{n-1} \prod_{s=\max \left\{n_{0}+1, k+1\right\}}^{n} \beta\left(\pi_{s-1}^{j}, d_{s-1}^{j}\right) \beta^{m_{k}^{j}}\left(\pi_{k-1}^{j}, d_{k-1}^{j}\right) \\
\leq & \gamma^{n-n_{0}} \sum_{k=1}^{n_{0}} \beta^{m_{k}^{j}}\left(\pi_{k-1}^{j}, d_{k-1}^{j}\right) \\
& +\sum_{k=n_{0}+1}^{n-1} \gamma^{n-k} \beta^{m_{k}^{j}}\left(\pi_{k-1}^{j}, d_{k-1}^{j}\right) \\
\leq & Q_{1}^{j} \gamma^{n}+\sum_{k=n_{0}+1}^{n-1} \gamma^{n-k+m_{k}^{j}} \leq Q_{1}^{j} \gamma^{n}+\gamma^{n} \frac{\gamma^{m_{n_{0}}^{j}-n_{0}-1}}{1-\gamma} \\
\leq & Q_{2}^{j} \gamma^{n},
\end{aligned}
$$

where $Q_{1}^{j}$ and $Q_{2}^{j}$ are nonnegative real numbers. Hence, we have

$$
d_{n}^{j} \leq \gamma^{n-n_{0}} \prod_{s=0}^{n_{0}} \beta\left(\pi_{s}^{j}, d_{s}^{j}\right) d_{0}^{j}+Q_{2}^{j} \gamma^{n}+\gamma^{n} \leq Q^{j} \gamma^{n},
$$

where $Q^{j}$ are nonnegative real numbers. Thus, for each $n \geq$ $n_{0}+1$,

$$
d\left(x_{n}, x_{n+1}\right)=d\left(y_{n}^{0}, y_{n}^{N}\right) \leq \sum_{j=1}^{N} d_{n}^{j} \leq \sum_{j=1}^{N} Q^{j} \gamma^{n} .
$$

Hence, for each $n \geq n_{0}+1$ and $m \in \mathbb{N}$, we have

$$
\begin{aligned}
d\left(x_{n}, x_{n+m}\right) & \leq d\left(x_{n}, x_{n+1}\right)+\cdots+d\left(x_{n+m-1}, x_{n+m}\right) \\
& \leq \sum_{j=1}^{N} Q^{j}\left[\gamma^{n}+\cdots+\gamma^{n+m-1}\right] \\
& \leq \sum_{j=1}^{N} Q^{j} \frac{\gamma^{n}}{1-\gamma} .
\end{aligned}
$$

Since $\gamma^{n} \rightarrow 0$ as $n \rightarrow+\infty,\left\{x_{n}\right\}$ is a Cauchy sequence and so $x_{n} \rightarrow x^{*} \in X$. If

$$
E=\left\{n \in \mathbb{N}: x_{n}=x^{*}\right\}
$$

and $\#(E)=\infty$, where $\#(E)$ is the cardinal number of $E$, then $x_{n+1} \in S\left(x_{n}\right)=S\left(x^{*}\right)$ and $x^{*} \in S\left(x^{*}\right)$. If $\#(E)<\infty$, then one can deduce that there exists $l \in \mathbb{N}$ such that $x_{n} \neq x^{*}$ for all $n \in \mathbb{N}$ with $n \geq l$. This means $H\left(S\left(x_{n}\right), S\left(x^{*}\right)\right)>0$ and $d\left(x_{n}, x^{*}\right)>0$ for each $n \geq l$. Since $x_{n} \rightarrow x^{*} \in X$, for a sequence $\left\{x_{n}\right\}$ with $x_{n} \in\left[x_{n}\right]_{G}^{N} \cap S\left(x_{n}\right)$ for each $n \in \mathbb{N}$, there is a subsequence $\left\{x_{n_{m}}\right\}_{m \in \mathbb{N}} \in X$ such that $\left(x_{n_{m}}, x\right) \in E(G)$ for each $m \in \mathbb{N}$. Thus, we have

$$
\begin{aligned}
& d\left(x^{*}, S\left(x^{*}\right)\right) \leq d\left(x^{*}, x_{n_{m+1}}\right)+d\left(x_{n_{m+1}}, S\left(x^{*}\right)\right) \\
& \leq d\left(x^{*}, x_{n_{m+1}}\right)+H\left(S\left(x_{n_{m}}\right), S\left(x^{*}\right)\right) \leq d\left(x^{*},\right. \\
& \left.x_{n_{m+1}}\right)+\beta\left(H\left(S\left(x_{n_{m}}\right), S\left(x^{*}\right)\right)\right. \\
& \left.d\left(x_{n_{m}}, x^{*}\right)\right) d\left(x_{n_{m}}, x^{*}\right) .
\end{aligned}
$$


Taking the limit as $m \rightarrow \infty$, in the last inequality, we have $d\left(x^{*}, S\left(x^{*}\right)\right)=0$. Since $S\left(x^{*}\right)$ is closed, it follows that $x^{*} \in$ $S\left(x^{*}\right)$. This completes the proof.

Remark 9. Taking $\beta(u, v)=\varphi(v)$ in Theorem 8 , we get main result of Sultana and Vetrivel's work which is Theorem 4.

Remark 10. We have Theorem 1 as a corollary to our Theorem 8 by taking $\beta(u, v)=\varphi(v), E(G)=X \times X$, and $N=1$.

Remark 11. Taking $\beta(u, v)=\mu$ in Theorem 8 , we can get the main result of [18].

Javahernia et al. [16] introduced the concept of weak lower semicontinuity in the following way.

Definition 12. A function $\phi:[0, \infty) \rightarrow[0, \infty)$ is said to be weak lower semicontinuous function if, for each bounded sequence $\left\{u_{n}\right\} \subset(0,+\infty)$, one has

$$
\lim _{n \rightarrow \infty} \inf \phi\left(u_{n}\right)>0 .
$$

Consistent with Javahernia et al. [16], we denote by $F$ the set of all functions $\phi:[0, \infty) \rightarrow[0, \infty)$ satisfying the abovementioned condition.

Theorem 13. Let $(X, d)$ be a complete metric space endowed with a graph and let $S: X \rightarrow C B(X)$ be a multivalued mapping such that

(1) for all $x, y \in X$, with $x \neq y$ and $(x, y) \in E(G)$,

$$
H(S(x), S(y)) \leq d(x, y)-\phi(d(x, y))
$$

where $\phi:[0, \infty) \rightarrow[0, \infty)$ is such that $\phi(0)=0$, $\phi(v)<v$, and $\phi \in F$;

(2) if $u \in S(x)$ and $v \in S(y)$ are such that $d(u, v) \leq d(x, y)$, then $(u, v) \in E(G)$.

Assume that there exist $N \in \mathbb{N}$ and $x_{0} \in X$ such that

(a) $\left[x_{0}\right]_{G}^{N} \cap S\left(x_{0}\right) \neq 0$;

(b) for any sequence $\left\{x_{n}\right\}_{n \in \mathbb{N}} \in X$, if $x_{n} \rightarrow x$ and $x_{n} \in$ $\left[x_{n-1}\right]_{G}^{N} \cap S\left(x_{n-1}\right)$ for each $n \in \mathbb{N}$, then there is a subsequence $\left\{x_{n_{m}}\right\}_{m \in \mathbb{N}} \in X$ such that $\left(x_{n_{m}}, x\right) \in E(G)$ for each $m \in \mathbb{N}$.

Then, $S$ has a fixed point and the sequence $\left\{x_{n}\right\}_{n \in \mathbb{N}} \in X$ converges to the fixed point of $S$.

Proof. Define $\beta(u, v)=1-\phi(u) / u$ for all $u, v>0$. Since, for each bounded sequence $\left\{u_{n}\right\} \subset(0,+\infty)$, we have $\lim _{n \rightarrow \infty} \inf \phi\left(u_{n}\right)>0$, we have $\lim _{n \rightarrow \infty} \inf \left(\phi\left(u_{n}\right) / u_{n}\right)>0$. Thus, we have

$$
\lim _{n \rightarrow \infty} \sup \left(1-\frac{\phi\left(u_{n}\right)}{u_{n}}\right)=1-\lim _{n \rightarrow \infty} \inf \frac{\phi\left(u_{n}\right)}{u_{n}}<0 .
$$

This shows that $\beta \in \Lambda$. Also, we have

$$
\begin{aligned}
& H(S(x), S(y)) \\
& \quad \leq \beta(H(S(x), S(y)), d(x, y)) d(x, y) .
\end{aligned}
$$

Thus, by Theorem $8, w$ is fixed point of $S$. This completes the proof.

\section{Applications}

As an application of Theorem 8, we now establish the following theorem for mappings satisfying inequality (7) uniformly locally on an $\varepsilon$-chainable metric space.

Theorem 14. Let $(X, d)$ be a complete $\varepsilon$-chainable metric space and let $S: X \rightarrow C B(X)$ be a multivalued mapping such that, for all $x, y \in X$ with $x \neq y$ and $d(x, y)<\varepsilon$, there exists $\beta \in \Lambda$ satisfying

$$
\begin{aligned}
& H(S(x), S(y)) \\
& \quad \leq \beta(H(S(x), S(y)), d(x, y)) d(x, y) .
\end{aligned}
$$

Then, S has a fixed point.

Proof. We consider the graph $G$ with $V(G)=X$ and $E(G)=$ $\{(x, y) \in X \times X: d(x, y)<\varepsilon\}$. Evidently, $\Delta \subseteq E(G)$ and $G$ has no parallel edges. Then, one can easily check that $S$ is a generalized Mizoguchi-Takahashi $G$-contraction for the abovementioned chosen graph $G$. Let $x_{0} \in X$ and $x_{1} \in S\left(x_{0}\right)$. Since $(X, d)$ is $\varepsilon$-chainable, there is a path $\left(y^{i}\right)_{i=0}^{N}$ from $x_{0}$ to $x_{1}$; that is, $y^{0}=x_{0}, y^{N}=x_{1}$, and $\left(y^{i-1}, y^{i}\right) \in E(G)$ for each $i=1,2, \ldots, N$. Thus, there exists $N \in \mathbb{N}$ such that $\left[x_{0}\right]_{G}^{N} \cap S\left(x_{0}\right) \neq \emptyset$. If $\left\{x_{n}\right\}$ is a sequence in $X$ such that $\left\{x_{n}\right\}$ converges to some $x^{*} \in X$, then there exists a positive integer $n_{0}$ such that $d\left(x_{n}, x^{*}\right)<\varepsilon$ for each $n \geq n_{0}$. Therefore, we can obtain a subsequence $\left\{x_{n_{m}}\right\}$ of $\left\{x_{n}\right\}$ such that $d\left(x_{n_{m}}, x^{*}\right) \in$ $E(G)$ for all $m \in \mathbb{N}$. Thus, all the conditions of Theorem 8 hold and $S$ has a fixed point. This completes the proof.

Corollary 15 (see [25]). Let $(X, d)$ be a complete $\varepsilon$-chainable metric space and let $S: X \rightarrow C B(X)$ be a multivalued mapping such that, for all $x, y \in X$ with $x \neq y$ and $d(x, y)<\varepsilon$, there exists $\varphi \in \Omega$ satisfying

$$
H(S(x), S(y)) \leq \varphi(d(x, y)) d(x, y) .
$$

Then, S has a fixed point.

Proof. Take $\beta(u, v)=\varphi(v)$ in Theorem 14 .

\section{Competing Interests}

The authors declare that there is no conflict of interests regarding the publication of this paper.

\section{Acknowledgments}

This paper was funded by the Deanship of Scientific Research (DSR), King Abdulaziz University. The first and third authors, therefore, acknowledge technical and financial support of KAU. 


\section{References}

[1] S. Banach, "Sur les opérations dans les ensembles abstraits et leur application aux equations itegrales," Fundamenta Mathematicae, vol. 3, pp. 133-181, 1922.

[2] E. Kryeyszig, Introductory Functional Analysis with Applications, John Wiley \& Sons, New York, NY, USA, 1978.

[3] S. Nadler Jr., "Multi-valued contraction mappings," Pacific Journal of Mathematics, vol. 30, no. 2, pp. 475-488, 1969.

[4] W. Cholamjiak, P. Cholamjiak, and S. Suantai, "Convergence of iterative schemes for solving fixed point problems for multivalued nonself mappings and equilibrium problems," Journal of Nonlinear Science and Its Applications, vol. 8, no. 6, pp. 12451256, 2015.

[5] N. Hussain and P. Salimi, "Suzuki-Wardowski type fixed point theorems for $\alpha$-GF-contractions," Taiwanese Journal of Mathematics, vol. 18, no. 6, pp. 1879-1895, 2014.

[6] N. Hussain, J. Ahmad, L. Ćirić, and A. Azam, "Coincidence point theorems for generalized contractions with application to integral equations," Fixed Point Theory and Applications, vol. 2015, no. 1, article 78, 2015.

[7] N. Hussain, J. Ahmad, and A. Azam, "On Suzuki-Wardowski type fixed point theorems," Journal of Nonlinear Science and Its Applications, vol. 8, no. 6, pp. 1095-1111, 2015.

[8] N. Hussain and M. A. Taoudi, "Krasnosel'skii-type fixed point theorems with applications to Volterra integral equations," Fixed Point Theory and Applications, vol. 2013, no. 1, article 196, 2013.

[9] A. Latif and A. A. N. Abdou, "Multivalued generalized nonlinear contractive maps and fixed points," Nonlinear Analysis: Theory, Methods \& Applications, vol. 74, no. 4, pp. 1436-1444, 2011.

[10] A. Latif and D. T. Luc, "A general fixed point theorem for multivalued mappings that are not necessarily contractions and applications," Abstract and Applied Analysis, vol. 2014, Article ID 104762, 5 pages, 2014.

[11] H. K. Pathak, R. P. Agarwal, and Y. J. Cho, "Coincidence and fixed points for multi-valued mappings and its application to nonconvex integral inclusions," Journal of Computational and Applied Mathematics, vol. 283, pp. 201-217, 2015.

[12] R. Saadati, S. M. Vaezpour, and L. B. Ćirić, "Generalized distance and some common fixed point theorems," Journal of Computational Analysis and Applications, vol. 12, no. 1, pp. 157$162,2010$.

[13] W. Sintunavarat, D. M. Lee, and Y. J. Cho, "Mizoguchi-Takahashi's type common fixed point theorems without $T$-weakly commuting condition and invariant approximations," Fixed Point Theory and Applications, vol. 2014, no. 1, article 112, 10 pages, 2014.

[14] M. U. Ali, T. Kamran, W. Sintunavarat, and P. Katchang, "Mizoguchi-Takahashi's fixed point theorem with $\alpha-\eta$ functions," Abstract and Applied Analysis, vol. 2013, Article ID 418798, 4 pages, 2013.

[15] N. Mizoguchi and W. Takahashi, "Fixed point theorems for multivalued mappings on complete metric spaces," Journal of Mathematical Analysis and Applications, vol. 141, no. 1, pp. 177$188,1989$.

[16] M. Javahernia, A. Razani, and F. Khojasteh, "Common fixed point of the generalized Mizoguchi-Takahashi's type contractions," Fixed Point Theory and Applications, vol. 2014, no. 1, article 195, 12 pages, 2014.
[17] J. Jachymski, "The contraction principle for mappings on a metric space with a graph," Proceedings of the American Mathematical Society, vol. 136, no. 4, pp. 1359-1373, 2008.

[18] I. Beg, A. R. Butt, and S. Radenović, "The contraction principle for set valued mappings on a metric space with a graph," Computers \& Mathematics with Applications, vol. 60, no. 5, pp. 1214-1219, 2010.

[19] J. Ahmad, N. Hussain, A. R. Khan, and A. Azam, "Fixed point results for generalized multi-valued contractions," Journal of Nonlinear Science and Its Applications, vol. 8, no. 6, pp. 909-918, 2015.

[20] F. Bojor, "Fixed point theorems for Reich type contractions on metric spaces with a graph," Nonlinear Analysis: Theory, Methods \& Applications, vol. 75, no. 9, pp. 3895-3901, 2012.

[21] R. Espnola and W. A. Kirk, "Fixed point theorems in R-trees with applications to graph theory," Topology and its Applications, vol. 153, pp. 1046-1055, 2006.

[22] N. Hussain, J. Ahmad, and A. Azam, "Generalized fixed point theorems for multi-valued $\alpha$ - $\psi$-contractive mappings," Journal of Inequalities and Applications, vol. 2014, article 348, 2014.

[23] N. Hussain, S. Al-Mezel, and P. Salimi, "Fixed points for $\psi$ graphic contractions with application to integral equations," Abstract and Applied Analysis, vol. 2013, Article ID 575869, 11 pages, 2013.

[24] N. Hussain, M. Arshad, A. Shoaib, and Fahimuddin, "Common fixed point results for $\alpha$ - $\psi$-contractions on a metric space endowed with graph," Journal of Inequalities and Applications, vol. 2014, article 136, 2014.

[25] A. Sultana and V. Vetrivel, "Fixed points of MizoguchiTakahashi contraction on a metric space with a graph and applications," Journal of Mathematical Analysis and Applications, vol. 417, no. 1, pp. 336-344, 2014. 


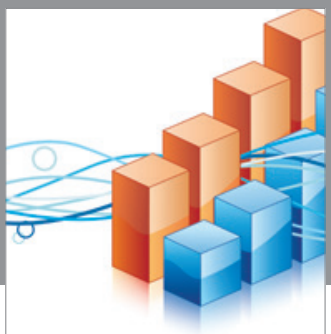

Advances in

Operations Research

vatem alat4

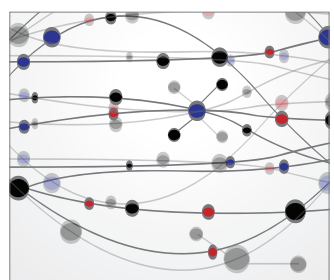

\section{The Scientific} World Journal
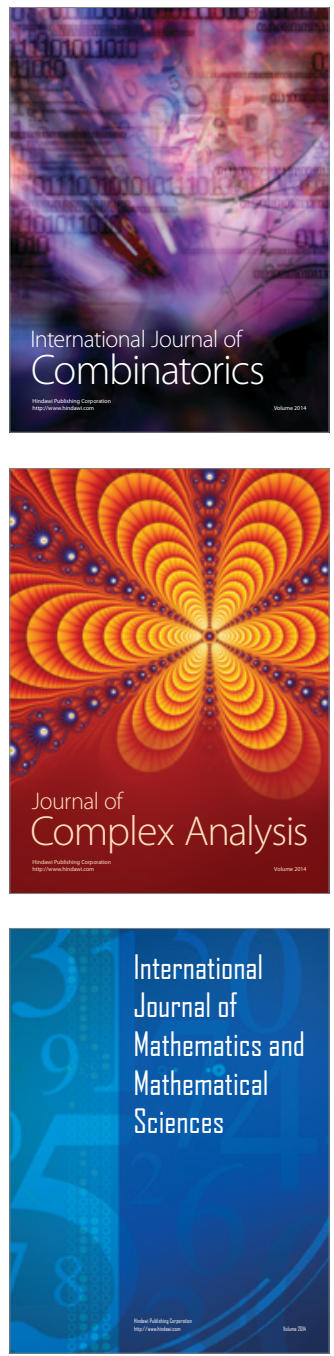
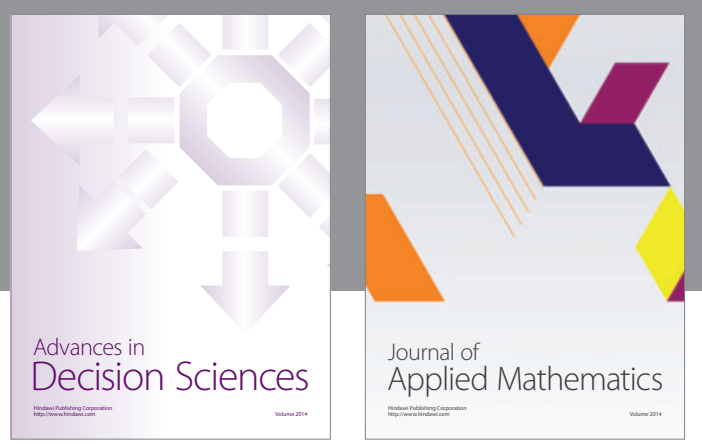

Algebra

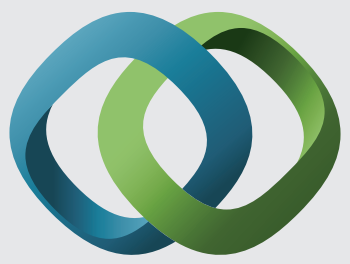

\section{Hindawi}

Submit your manuscripts at

http://www.hindawi.com
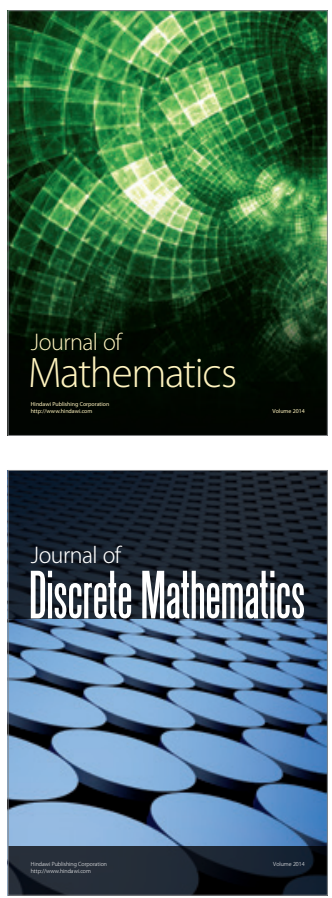

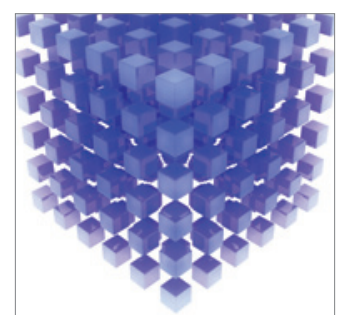

Mathematical Problems in Engineering
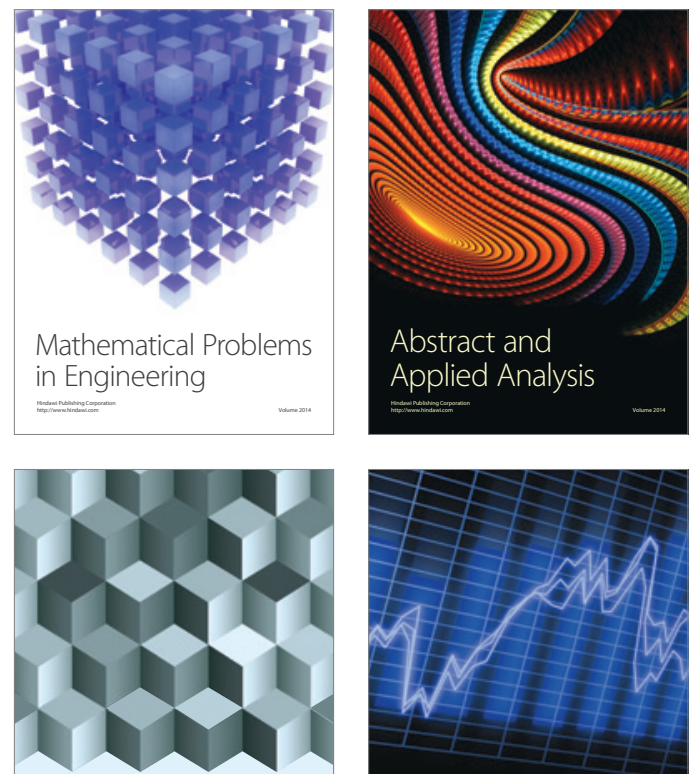

Journal of

Function Spaces

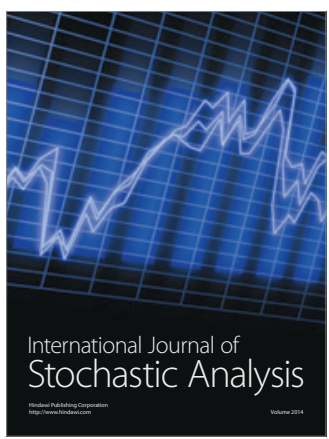

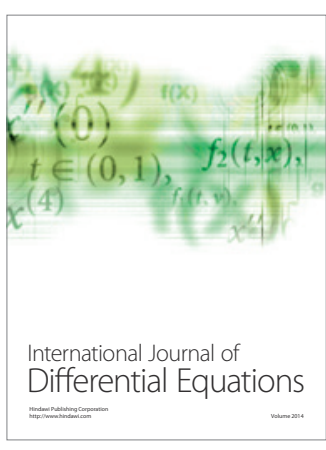
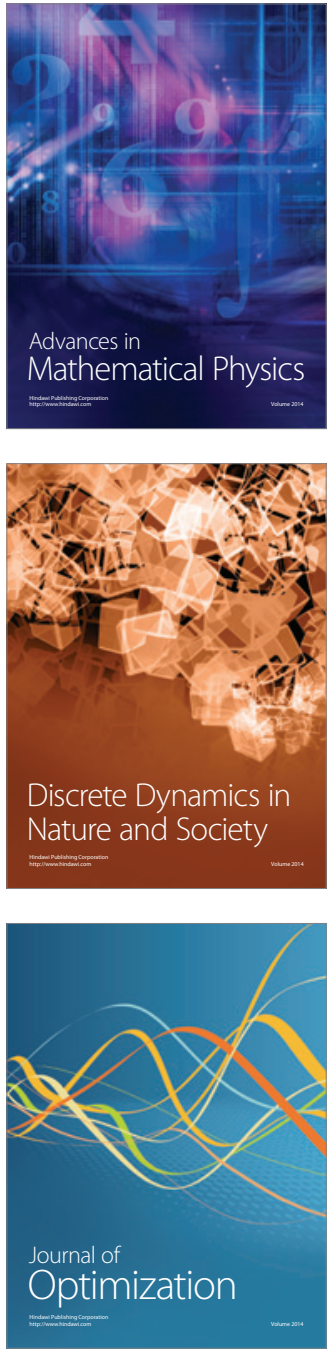